\title{
Nevoid Trichostasis Spinulosa: Dermoscopic Point of View
}

\author{
${ }^{1}$ Balachandra S Ankad, ${ }^{2}$ Swapnil Shah, ${ }^{3}$ Anirudh A Mallapur
}

\begin{abstract}
Trichostasis spinulosa (TS) is a common yet underdignosed condition affecting hair follicles. Diagnosis is based on the clinical features, hair mount, and dermoscopy. Here, the authors describe a case of TS in a nevoid distribution wherein dermoscopy aided the diagnosis.
\end{abstract}

Keywords: Dermoscopy, Nevoid trichostasis spinulosa, Tufted hair.

How to cite this article: Ankad BS, Shah S, Mallapur AA. Nevoid Trichostasis Spinulosa: Dermoscopic Point of View. Int J Dermoscop 2017;1(2):65-66.

Source of support: Nil

Conflict of interest: None

\section{INTRODUCTION}

Sir,

Trichostasis spinulosa is a common yet underdignosed condition affecting hair follicles. It occurs on the face especially the nose. Diagnosis is based on the clinical features, hair mount, and dermoscopy. Rarely, it can present in nevoid distributions, making diagnosis a difficult task. ${ }^{1}$

A 2-month-old baby was brought with a history of sudden appearance of new hairs on the back since 1 week. On examination, multiple tiny scattered black dots were noted in the interscapular area (Fig. 1). Diffuse erythema was present. Keratosis pilaris (KP) and eruptive vellous hair cysts (VHCs) were considered as differentials. Dermoscopy demonstrated tuft of entangled hairs forming aggregation and emerging from a single follicle with 5 to 15 vellous hairs (Fig. 2) and white dots in regular, equidistant distribution. Dermoscopy of KP shows looped and coiled hairs embedded in epidermis

\footnotetext{
${ }^{1}$ Professor and Head, ${ }^{2}$ Consultant, ${ }^{3}$ Junior Resident

${ }^{1,3}$ Department of Dermatology, S. Nijalingappa Medical College and H.S.K Hospital \& Research Centre, Bagalkot, Karnataka India

${ }^{2}$ Department of Dermatology, Skin and Laser Clinic, Solapur Maharashtra, India

Corresponding Author: Balachandra S Ankad, Professor and Head, Department of Dermatology, S. Nijalingappa Medical College and H.S.K Hospital \& Research Centre, Bagalkot Karnataka, India, Phone: +919980410056, e-mail: drbsankad@ gmail.com
}

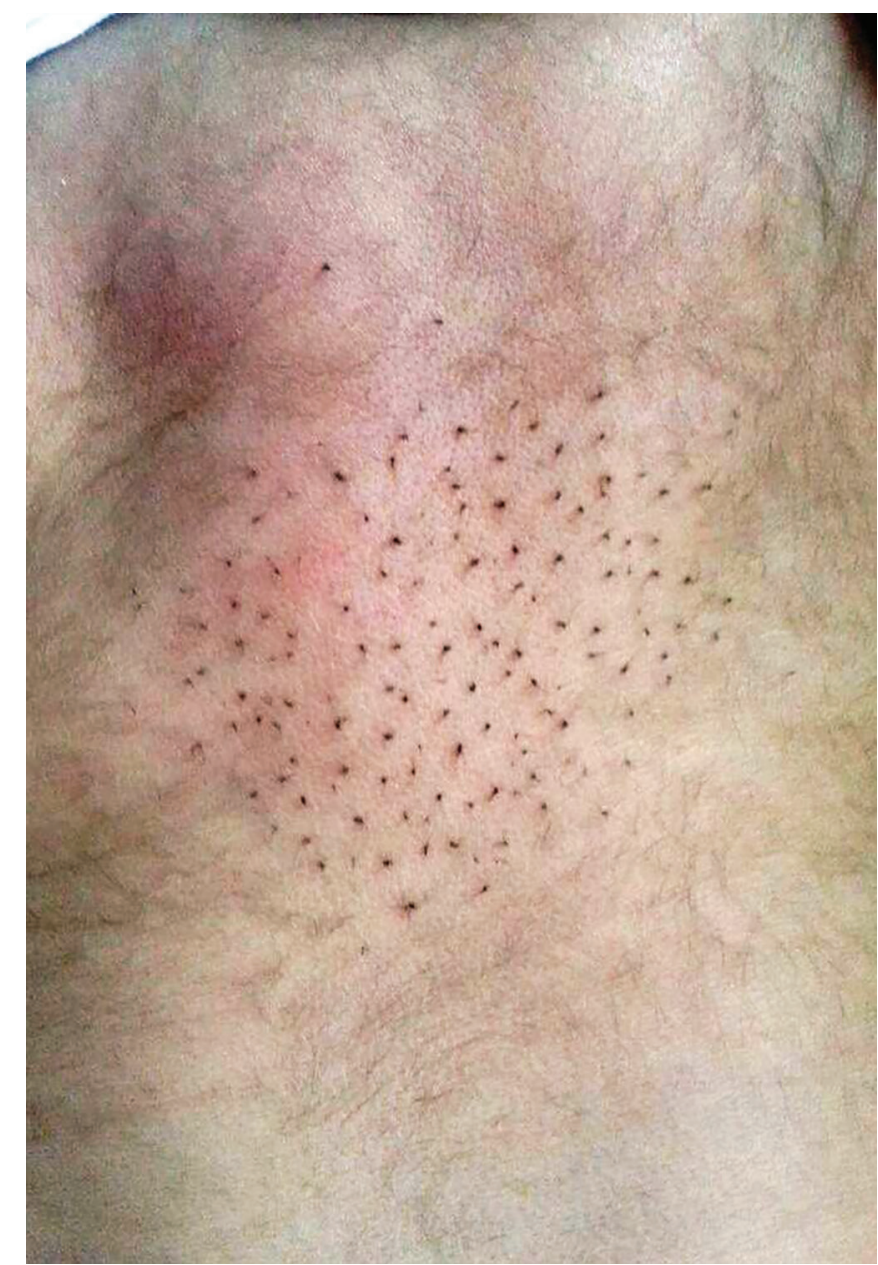

Fig. 1: Clinical image showing scattered aggregation of tuft of hair appearing as tiny black dots

with perifollicular erythema and scaling, whereas nonfollicular, pale blue areas with indistinct borders are noted in eruptive VHC. ${ }^{2-4}$ In this case, dermoscopy demonstrated tuft of entangled hairs in each follicular opening without peripilar erythema and scaling. White dots represent sweat duct openings. Thus, based on dermoscopic findings, a diagnosis of nevoid TS (NTS) was made. Hence, dermoscopy aids in the diagnosis of NTS as a noninvasive diagnostic procedure.

\section{ACKNOWLEDGMENT}

The authors acknowledge the help of Dr Arun Inamadar, Professor and Head, Department of Dermatology, BLDE'S Medical College for his assistance in working up this case. 


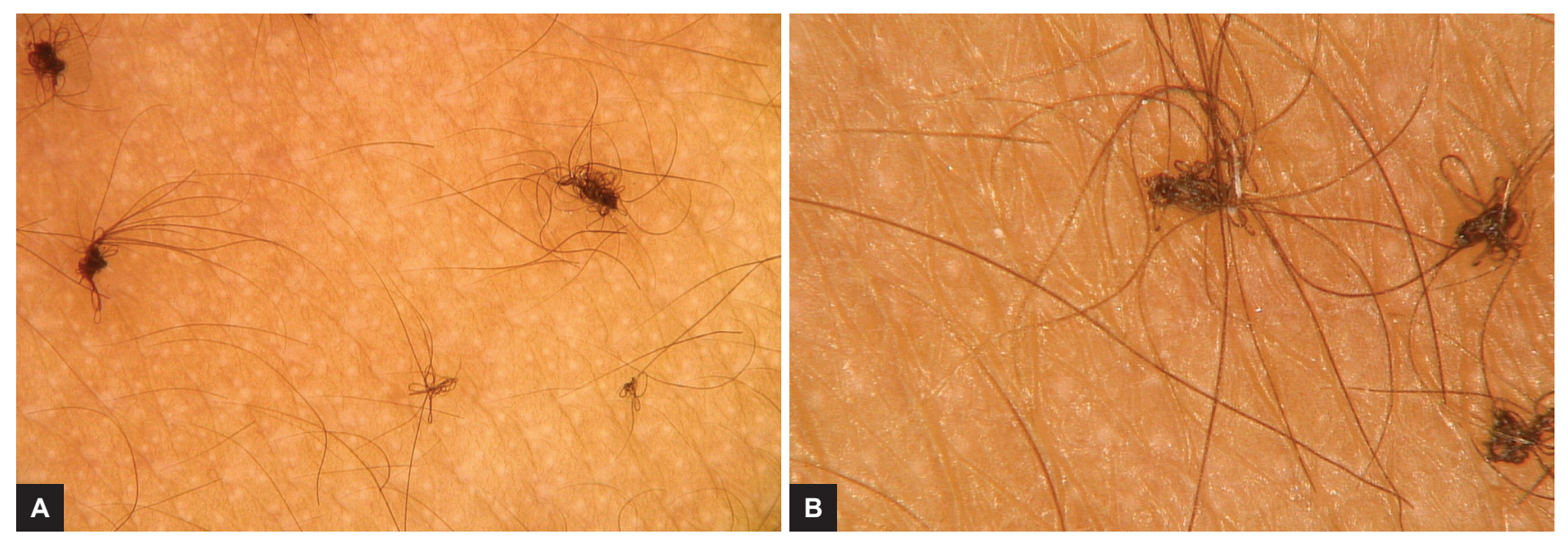

Figs 2A and B: Dermoscopy showing tuft of hairs entangled into aggregation (A), 20× magnification and B, 70× magnification, nonpolarized mode; FotoFinder ${ }^{\circledR}$, Germany) and regularly arranged white dots

\section{REFERENCES}

1. Camacho-Martinez FM. Hypertrichosis. In: Blume-Peytavi U, Tosti A, Whiting D, Trüeb R, editors. Hair growth and disorders. 1st ed. Berlin: Springer; 2008. p. 333-356.

2. Olszewska M, Rudnicka L, Rakowska A, KowalskaOledzka E, Slowinska M. Trichoscopy. Arch Dermatol 2008 Aug;144(8):1007.
3. Thomas M, Khopkar US. Keratosis pilaris revisited: Is it more than just a follicular keratosis? Int J Trichol 2012 Oct;4(4): 255-258.

4. Togawa Y, Takada S, Wakabayashi S, Kambe N, Matsue H. Dermoscopic findings in eruptive vellous hair cysts: a case report. Austin J Dermatolog 2014;1(1):1004. 